\title{
Left ventricular volumes, ejection fraction, and plasma proatrial natriuretic factor (1-98) after withdrawal of enalapril treatment initiated early after myocardial infarction
}

\author{
Vernon V S Bonarjee, Torbjørn Omland, Dennis W T Nilsen, Steen Carstensen, \\ Jens Berning, Magnus Edner, Kenneth Caidahl on behalf of the CONSENSUS II \\ multi-echo study group
}

\section{Division of \\ Cardiology, Department of Medicine, Central Hospital in Rogaland, Stavanger, Norway \\ V V S Bonarjee \\ T Omland \\ D W T Nilsen \\ Division of \\ Cardiology, \\ Department of \\ Medicine, \\ Rigshospitalet, \\ University of \\ Copenhagen, \\ Copenhagen, \\ Denmark \\ $S$ Carstensen \\ J Berning \\ Department of \\ Cardiology, Thoracic \\ Clinics, Karolinska \\ Hospital, Stockholm, \\ Sweden \\ M Edner \\ Department of \\ Clinical Physiology, Sahlgrenska \\ University Hospital, \\ Gothenburg, Sweden \\ K Caidahl}

Correspondence to:

of Clinical Physiology,

of Clinical Physiology,

Sahlgrenska University

Hospital, S-413 45,
Gothenburg, Sweden

Accepted for publication

21 December 1994

CONSENSUS II multi-

echo study group:

investigators

V V S Bonarjee,

$C$ von Brandis,

D W T Nilsen, T Omland

(Central Hospital in

Rogaland, Stavanger,

Norway); S Ali, J Berning,

$S$ Carstensen

S Carstensen

Copenhagen, Denmark

Copenhagen, Denmark

(site of core laboratory))

Frolund, K Lindvall,

M Quintana (Söder

Hospital, Stockholm,

Sweden); O Beck-Hans

M Beckman Suurküla

Caidahl, I Wallenti

(

\begin{abstract}
Objectives-To assess whether the reduction in left ventricular dilatation after acute myocardial infarction obtained by early administration of angiotensin converting enzyme inhibitors depends on continuous treatment.

Design-Prospective observational and cross sectional study of withdrawal of randomised treatment with enalapril or placebo.

Patients-106 patients on 6 months trial treatment after an acute myocardial infarction.

Main outcome measures-Left ventricular volumes and ejection fraction as assessed by echocardiography and circulating proatrial natriuretic factor (1-98) before and 4-6 weeks after withdrawal of treatment.

Results-There were no significant changes (mean (SD)) in left ventricular systolic $\left(0.7(4.7) \mathrm{ml} / \mathrm{m}^{2}\right)$ and diastolic $\left(0.4(6.6) \mathrm{ml} / \mathrm{m}^{2}\right)$ volume indices, ejection fraction ( $-0.9(6) \%)$, and proatrial natriuretic factor (172 (992) pmol/1) after withdrawal of enalapril. The significantly lower left ventricular volumes observed with 6 months of enalapril therapy after acute myocardial infarction, as compared with placebo, were maintained 6 weeks after drug withdrawal.

Conclusion-The results show that the benefit of 6 months of enalapril treatment initiated early after myocardial infarction is maintained for at least 6 weeks after drug withdrawal, suggesting that the treatment effect on left ventricular structure is not reversed by changes in loading conditions caused by subsequent drug withdrawal.
\end{abstract}

(Br Heart f 1995;73:506-510)

Keywords: left ventricular dilatation; acute myocardial infarction; enalapril withdrawal; proatrial natriuretic factor (1-98)

The increase in left ventricular volume after acute myocardial infarction was reduced by treatment with angiotensin converting enzyme inhibitors. ${ }^{1-3}$ Because these drugs lower cardiac filling pressures and systemic blood pressure they may result in decreased left ventricular volumes and higher ejection fractions. Previous studies have shown that in patients with $Q$ wave infarction, anteroapical location and infarct size are major determinants of infarct expansion. ${ }^{4}$ It has also been reported that expansion occurs predominantly when the infarct is situated in the region of the left ventricle with greatest curvature, ${ }^{5}$ suggesting that wall stress is directly related to the degree of left ventricular dilatation after myocardial infarction. The reduction in afterload achieved with angiotensin converting enzyme inhibition started soon after acute myocardial infarction reduces left ventricular wall stress; this may reduce infarct expansion, remodelling, and subsequent left ventricular dilatation. The effect of angiotensin converting enzyme inhibitors on left ventricular size and function may also partly be the result of inhibition of the local myocardial tissue renin angiotensin system ${ }^{67}$; this may modify the adaptive process occurring in the myocardium after ischaemic injury.

Whether continued long-term treatment with angiotensin converting enzyme inhibitors is necessary to maintain reduced volumes resulting from treatment early after myocardial infarction has not been fully examined. However, it has previously been reported that left ventricular volumes do not change during the first 48 hours after withdrawal of 3 months of captopril treatment initiated early after myocardial infarction. ${ }^{1} \mathrm{~A}$ withdrawal period of 48 hours may be enough to reveal reversible haemodynamic changes, but may not be sufficient to demonstrate a reversible effect on structural changes, especially those caused by altered tissue angiotensin II activity. This study was designed to determine whether the lower left ventricular volumes obtained by converting enzyme inhibition, initiated early after myocardial infarction, were maintained over an extended period of time independently of continuous treatment.

Serial echocardiography was performed before and 4-6 weeks after withdrawal of enalapril in a substudy of the Cooperative New Scandinavian Enalapril Survival Study (CONSENSUS II). ${ }^{8}$ Plasma proatrial natriuretic factor (1-98), which has been shown to be a sensitive marker of cardiac filling pressures $^{9}$ and a marker of symptomless left ventricular dysfunction, ${ }^{10}$ was also investigated serially in this study. 


\section{Patients and methods \\ STUDY DESIGN}

The CONSENSUS II trial was a multicentre, double blind, randomised, placebo controlled study evaluating the effect of early enalapril treatment on 6 month mortality after acute myocardial infarction. Patients received $1 \mathrm{mg}$ of enalaprilat or placebo within 24 hours after a confirmed myocardial infarction, followed by oral treatment for 6 months. Seven centres recruited patients to an echocardiographic substudy using a common protocol, the results of which have been reported. ${ }^{3}$ Patients on trial medication at the final examination were examined with cross sectional echocardiography before and 4-6 weeks after withdrawal of the trial drug in four of these centres (see list of centres). Trial medication was discontinued in all patients. The treatment code, however, was not revealed after withdrawal and all examinations and measurements were done double blinded. Concurrent treatment was kept unchanged during the withdrawal period and open converting enzyme inhibitor therapy was not initiated in any patient during this period.

\section{STUDY POPULATION}

Patients with chest pain lasting more than 20 minutes within the past 24 hours, presenting with new electrocardiographic changes compatible with acute myocardial infarction and/ or enzymatic evidence of myocardial necrosis were included in the CONSENSUS II study after informed consent. Patients with hypotension (blood pressure $<105 / 65 \mathrm{~mm}$ $\mathrm{Hg}$ ); significant valvar disease; severe hepatic, renal, or haematological disorders; severe heart failure; and those using converting enzyme inhibitors were not included. The study was approved by the regional ethics committees. Patients taking trial medication according to protocol at the final examination were eligible for follow up after drug withdrawal.

\section{METHODS OF ASSESSMENT \\ Echocardiography}

Cross sectional echocardiography was performed by experienced physicians or technicians before and after withdrawal of the trial drug. Apical two and four chamber views

Table 1 Baseline characteristics before randomised treatment

\begin{tabular}{lcc}
\hline & Placebo $(n=78)$ & Enalapril $(n=58)$ \\
\hline Mean (SD) age (y) & $64 \cdot 7(10 \cdot 4)$ & $64 \cdot 8(10 \cdot 4)$ \\
Males (\%) & 78 & 74 \\
Anterior wall infarction (\%) & 58 & 52 \\
Q wave infarction (\%) & 72 & 69 \\
Mean (SD) heart rate & $76(13)$ & $75(14)$ \\
Systolic blood pressure (mm Hg) (mean (SD)) & $129 \cdot 5(18 \cdot 6)$ & $129 \cdot 3(16 \cdot 8)$ \\
Diastolic blood pressure (mm Hg) (mean (SD)) & $80 \cdot 0(11 \cdot 4)$ & $78 \cdot 1(10 \cdot 8)$ \\
Treatment: & 58 & 69 \\
Thrombolytic (\%) & 64 & 64 \\
$\beta$ Blocker (\%) & 59 & 62 \\
Intravenous GTN (\%) & 33 & 35 \\
Intravenous diuretics (\%) & 91 & 93 \\
Aspirin (\%) & 19 & 12 \\
Calcium channel blockers (\%) & 55 & 67 \\
Heparin (\%) & 15 & 21 \\
Warfarin (\%) & & \\
\hline
\end{tabular}

No significant differences were found between treatment groups. GTN, glyceryl trinitrate. were recorded according to the recommendations of the American Society of Echocardiography ${ }^{11}$ and stored on video tape for later analysis. The second examination was performed 4-6 weeks after withdrawal of trial medication by the same observer using the same equipment. Patients were examined in the left lateral supine position by commercially available ultrasound equipment (Acuson 128 (Mountain View, CA, USA), Aloka SSD 870 (Aloka Co, Tokyo, Japan) and Vingmed CFM 750 (Vingmed Sound, Horten, Norway). Complete cardiac cycles were digitised from the video recordings for computer assisted analysis. Analyses of all recordings were performed at a core laboratory by one observer, unaware of trial medication or clinical data. Biplane left ventricular volumes were calculated from planimetric area tracings of two and four chamber end diastolic and end systolic frames using the disc summation method (modified Simpson's rule). The methods and data on reproducibility have been reported elsewhere. ${ }^{3}$

\section{Plasma proatrial natriuretic factor (1-98)}

Blood samples for analysis of plasma proatrial natriuretic factor were drawn by direct venepuncture into chilled tubes containing ethylenediaminetetraacetic acid and aprotinin (500 kallikrein inactivator units $/ \mathrm{ml}$ blood) after at least 30 minutes of supine rest at the time of echocardiography. The test tubes were centrifuged and plasma samples were stored at $-70^{\circ} \mathrm{C}$ pending analysis. Proatrial natriuretic factor concentrations were determined as described previously by a specific radioimmunoassay method without prior extraction. ${ }^{12}$ All results are a mean of two parallel assays of each sample.

\section{STATISTICAL ANALYSIS}

Echocardiographic measurements of volumes, ejection fractions, and proatrial natriuretic factor in the enalapril group were compared with those of the placebo group before and 4-6 weeks after withdrawal of trial treatment. Changes over time were analysed in both groups and compared. Longitudinal data were compared as paired observations. Data at each time point from patients in different cohorts were compared by an unpaired test. Statistical significance for within group changes were assessed by the signed rank test, and for between group differences by the Wilcoxon rank sum test. Results are presented as means (SD). All $P$ values are two sided.

\section{Results}

One hundred and thirty six patients, 78 in the placebo and 58 in the enalapril group, on trial drug at the end of the treatment period were re-examined by echocardiography between 4 and 6 weeks after drug withdrawal. At the time of withdrawal the enalapril group were taking a mean of $16.7 \mathrm{mg}$ of trial drug. The target dose of $20 \mathrm{mg}$ day was being used by $74 \%$ of the patients. Table 1 presents the baseline characteristics of these patients. As 
Table 2 Characteristics before withdrawal

\begin{tabular}{lcc}
\hline & Placebo $(n=78)$ & Enalapril $(n=58)$ \\
\hline Heart rate (mean (SD)) & $65(12)$ & $65(10)$ \\
Blood pressure (mm Hg)(mean (SD)) & $139.0(20 \cdot 9)$ & $134 \cdot 6(22.5)$ \\
Systolic & $81 \cdot 7(9 \cdot 6)$ & $80 \cdot 8(11 \cdot 8)$ \\
Diastolic & & \\
Treatment (\%): & 64 & 64 \\
$\beta$ Blocker & 19 & 12 \\
Calcium channel blockers & 91 & 93 \\
Aspirin & 26 & 24 \\
Oral diuretics & & \\
\hline
\end{tabular}

No significant differences were found between treatment groups.

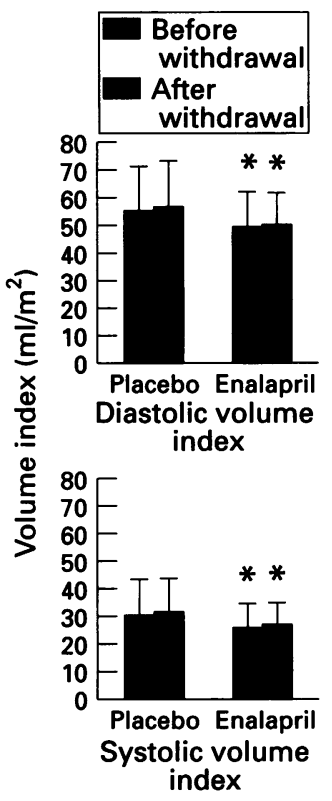

Left ventricular volume indices (mean (1 SD) at the end of treatment period and 4-6 weeks after drug withdrawal in 78 placebo and 58 enalapril treated patients. ${ }^{\star}$ Enalapril $v$ placebo; $P<0.05$. Differences in volume changes between the two groups were not significant during this period. shown, there were no significant differences at baseline in clinical characteristics and medication between the treatment groups. The withdrawal study was initially designed to include only patients with $Q$ wave infarction. After the premature termination of the main $\mathrm{CON}$ SENSUS II study was known, all patients on trial drug at their final examination were included in order to increase the sample size. Consequently, the percentage of patients with $Q$ wave infarction is higher than in the main CONSENSUS II population. Table 2 gives the patient characteristics and concomitant treatment before withdrawal.

In the intervention study before drug withdrawal we showed a reduction in volume expansion and significantly lower volumes 1 and 6 months after myocardial infarction with enalapril treatment as compared with placebo. ${ }^{3}$ Similarly, in the present patient population, diastolic and systolic volume indices were significantly lower in patients receiving enalapril rather than placebo at the end of the intervention period before withdrawal and remained significantly lower in enalapril treated patients 4-6 weeks after withdrawal (figure). In the placebo group systolic volume index increased significantly $(0.9$ $\left.(5 \cdot 1) \mathrm{ml} / \mathrm{m}^{2} \mathrm{P}<0.05\right)$ and diastolic volume index increased too, but not significantly $(1 \cdot 3$ $\left.(6.3) \mathrm{ml} / \mathrm{m}^{2} ; P=0.07\right) 4-6$ weeks after drug withdrawal. Changes in systolic and diastolic volume indices were not significant in the group of patients withdrawn from enalapril $\left(0.7(4.7) \mathrm{ml} / \mathrm{m}^{2}\right.$ and $0.4(6.6) \mathrm{ml} / \mathrm{m}^{2}$ respectively). However, differences in volume changes between the enalapril group and the placebo group of patients were not significant during this period.

Changes in diastolic and systolic volume indices were also evaluated in a subgroup of patients with $Q$ wave infarction. In the placebo group the diastolic and systolic volume indices increased by $2 \cdot 1(7 \cdot 2) \mathrm{ml} / \mathrm{m}^{2}(P=$ $0.03)$ and $0.8(6.5) \mathrm{ml} / \mathrm{m}^{2}(P=0.057)$ respectively. A significant change in systolic volume

Table 3 Plasma proatrial natriuretic factor (1-98)

\begin{tabular}{|c|c|c|c|c|c|c|}
\hline & \multicolumn{3}{|c|}{ Placebo } & \multicolumn{3}{|c|}{ Enalapril } \\
\hline & $n$ & $\begin{array}{l}\text { Mean } \\
\text { (pmolll) }\end{array}$ & $S D$ & $n$ & $\begin{array}{l}\text { Mean } \\
\text { (pmolll) }\end{array}$ & $S D$ \\
\hline $\begin{array}{l}\text { Before withdrawal } \\
4-6 \text { weeks after withdrawal } \\
\text { Change after withdrawal }\end{array}$ & $\begin{array}{l}78 \\
66 \\
62\end{array}$ & $\begin{array}{l}1289^{\star} \\
1145 \\
-97\end{array}$ & $\begin{array}{r}960 \\
1064 \\
1266\end{array}$ & $\begin{array}{l}57 \\
52 \\
49\end{array}$ & $\begin{array}{l}1040^{\star} \\
1105 \\
172\end{array}$ & $\begin{array}{r}926 \\
1052 \\
992\end{array}$ \\
\hline
\end{tabular}

index $\left(1.9(5.5) \mathrm{ml} / \mathrm{m}^{2} ; \mathrm{P}=0.01\right)$ but not in diastolic volume index $(0 \cdot 7(7 \cdot 3), P=N S)$ was observed in patients with $Q$ wave infarction withdrawn from enalapril. The differences in changes between placebo and enalapril treated patients with $Q$ wave infarction were not significant.

At the end of the intervention period and before the trial drug was stopped, the ejection fraction was $46(9) \%$ in the placebo and 49 (8)\% in the enalapril treated patients $(P=$ 0.09). During the withdrawal period, the ejection fraction did not change significantly in either treatment group (placebo -0.8 (6)\% $v$ enalapril $-0.9(6) \%$ ) and between group differences remained essentially unchanged at the end of the withdrawal period (placebo $45(9) \% v$ enalapril $48(8) \%, P$ $=0.08$ ). However, in patients with $Q$ wave infarction, the ejection fraction was significantly reduced in the group of patients withdrawn from enalapril treatment $(-3 \cdot 1$ $(7 \cdot 2) \%, P=0.005)$, but not in the placebo group. This difference between enalapril and placebo treated patients was of borderline significance $(P=0.054)$.

Before the study medication was stopped, the enalapril group of patients showed significantly lower concentrations of plasma proatrial natriuretic factor than the placebo group. Although inter and intra group changes were not statistically significant after withdrawal, significant between group differences in proatrial natriuretic factor were no longer apparent at the end of the withdrawal period (table 3).

\section{Discussion}

This trial was designed to evaluate the effect of drug withdrawal after 6 months of enalapril treatment started early after acute myocardial infarction in an unselected group of patients. We found significantly lower left ventricular volumes after 6 months of enalapril treatment than after placebo. This accorded with previously reported results from the treatment period. ${ }^{3}$ The results of the present withdrawal study show that this between group difference in left ventricular volumes was maintained for 4-6 weeks after enalapril treatment ended.

Nearly $46 \%$ of patients with myocardial infarction experience left ventricular dilatation during the first 4 weeks after infarction. ${ }^{13}$ In most patients this process is halted, but in some dilatation progresses. Studies evaluating the effect of early angiotensin converting enzyme inhibition after acute myocardial infarction showed that treatment significantly reduces left ventricular dilatation during the first months. ${ }^{13}$ These drugs have systemic and local actions and the mechanism by which they act is complicated and not fully determined. The effect on left ventricular remodelling may be predominantly structural. However, optimised loading conditions may be necessary to maintain this effect. We found that the effect of 6 months of enalapril treatment, initiated early after myocardial 
infarction, on left ventricular volumes was not rapidly reversed after drug withdrawal, suggesting that early treatment has an effect on left ventricular structure that is not reversed by changes in loading conditions caused by subsequent drug withdrawal.

Results from two large clinical trials, GISSI-3 and ISIS-4 $4^{14}$ document that early angiotensin converting enzyme inhibition reduces 6 week mortality in an unselected group of patients after acute myocardial infarction. These results, together with previously reported data, ${ }^{13}$ indicate that treatment with converting enzyme inhibition may be used in an unselected patient population soon after myocardial infarction to reduce shortterm mortality and prevent left ventricular dilatation. The present study indicates that converting enzyme inhibitors may be withdrawn after an initial treatment period in an unselected patient population without the risk of rapid left ventricular remodelling.

Previous reports showed a benefit of enalapril treatment on left ventricular volumes in patients with chronic symptomatic ${ }^{16}$ and asymptomatic $^{17}$ heart failure. Improved mortality was also shown with long-term angiotensin converting enzyme inhibition in patients with chronic heart failure ${ }^{18-20}$ as well as in patients with symptomatic ${ }^{21}$ and asymptomatic ${ }^{22}$ heart failure after myocardial infarction. Moreover, withdrawal of angiotensin converting enzyme inhibition in patients with symptomatic heart failure leads to clinical deterioration. ${ }^{23}$ In the present study we found a significant increase in systolic volume and a trend towards diastolic volume expansion in patients in the placebo group during the withdrawal period. Changes were also significant in a subgroup of patients with $Q$ wave infarction, and in this subgroup a significant increase in systolic volume was also seen in patients in the enalapril group. We also showed a significant deterioration in ejection fraction after withdrawal of enalapril in patients with $Q$ wave infarction. These findings accord with studies that showed a continued left ventricular expansion in some patients after myocardial infarction. ${ }^{13}$ Continued converting enzyme inhibition may therefore have additional benefit in selected patients such as those with $Q$ wave infarction or in patients with clinical heart failure.

In addition to left ventricular volumes, we evaluated the effect of enalapril withdrawal on plasma concentrations of proatrial natriuretic factor. It is well established that plasma concentrations of atrial natriuretic factor (99-126) are closely related to cardiac filling pressures. ${ }^{24}$ Recent reports suggest that the $\mathrm{N}$-terminal fragment of the atrial natriuretic factor pro-hormone-termed proatrial natriuretic factor (1-98)-is an even more sensitive marker of left ventricular function and prognosis in cardiac disease than atrial natriuretic factor (99-126). ${ }^{102526}$ In addition, because of enhanced in vivo stability and subsequent higher plasma concentrations, the analytic procedure is simplified. ${ }^{12}$ As a result of higher circulating concentrations, proatrial natriuretic factor may also be less liable to rapid fluctuations in plasma concentrations than atrial natriuretic factor (99-126). Consequently, measurements of proatrial natriuretic factor may provide valuable information related to cardiac loading conditions that are complementary to data obtained from echocardiography alone.

The results demonstrate significantly lower plasma proatrial natriuretic factor (1-98) concentrations in the enalapril group than in the placebo group at the end of the trial period that were compatible with decreased cardiac filling pressures among enalapril treated patients. After withdrawal of the study drug neither group demonstrated significant changes in plasma proatrial natriuretic factor (1-98). However, the significantly lower concentration in the enalapril group, seen before drug withdrawal, was no longer evident 4-6 weeks after the end of treatment, mainly because there was a large increase in proatrial natriuretic factor concentration in a few patients. These findings indicate that some patients may experience adverse haemodynamic changes after withdrawal of converting enzyme inhibition that are not reflected by a rapid structural remodelling and subsequent volume expansion.

\section{STUDY LIMITATIONS}

This study was not designed to compare the effect of drug withdrawal with that of continued treatment, and does not preclude additional benefit of long-term angiotensin converting enzyme inhibition. The limited sample size did not allow subgroup analysis in patients with heart failure or detailed subgroup analysis of changes in pro4atrial natriuretic factor. Observers were unaware of the treatment code even after drug withdrawal. However, the time of examination was known. This may have exaggerated the within group changes during the withdrawal period but does not compromise the between treatment group comparisons.

\section{CLINICAL IMPLICATIONS}

In conclusion, the results of the present study indicate that cessation of 6 months of enalapril treatment initiated early after myocardial infarction does not lead to a rapid loss of treatment effect on left ventricular volumes, suggesting that treatment has an effect on structural changes that is independent of beneficial loading conditions. Prolonged treatment is therefore not needed to conserve the early benefit of early angiotensin converting enzyme inhibition after acute myocardial infarction. However, selected groups of patients may need continued treatment. An additional benefit of long-term enalapril treatment on left ventricular volumes as well as mortality may be expected in such patients.

We thank Professor Johan Sundsfiord, Institute of Medical Biology, University of Tromsø, for the analysis of plasma proANF concentrations.

This study was supported by a grant from Merck Research Laboratories (Norwegian and Scandinavian subsidiaries). 
1 Sharpe N, Smith H, Murphy J, Greaves S, Hart H Gamble G. Early prevention of left ventricular dysfunction after myocardial infarction with angiotensinconverting enzyme inhibition. Lancet 1991;337:872-6.

2 Pfeffer MA, Lamas GA, Vaughan DE, Parisi AF, Braunwald E. Effect of captopril on progressive ventricular dilatation after anterior myocardial infarction. N Engl ₹ Med 1988;319:80-6.

3 Bonariee VVS, Carstensen S, Caidahl K, Nilsen DWT, Edner M, Berning J. Attenuation of left ventricular Edner $M$, Berning J. Attenuation of left ventricular dilatation after acute myocardial infarction by early initiation of enalapril therapy. Am f Cardiol 1993;72: $1004-9$

4 Picard MH, Wilkins GT, Ray PA, Weyman MD. Natural history of left ventricular size and function after acute myocardial infarction. Assessment and prediction by echocardiographic surface mapping. Circulation 1993;82 484-94.

5 Pirolo JS, Hutchins GM, Moore GW. Infarct expansion: Pathologic analysis of 204 patients with a single myocardial infarction. ₹ Am Coll Cardiol 1986;7:349-54.

6 Grinstead WC, Young JB. The myocardial reninangiotensin system: Existence, importance, and clinical implications. Am Heart $\mathcal{F}$ 1992;123:1039-45.

7 Hirsch AT, Talsness CE, Schunkert H, Paul M, Dzau VJ. Tissue-specific activation of cardiac angiotensin converting enzyme in experimental heart failure. Circ Res 1991; 69:475-82.

8 Swedberg K, Held P, Kjekshus J, Rasmussen K, Rydén L, Wedel $\mathrm{H}$ on behalf of the CONSENSUS II study group. Effects of the early administration of enalapril on mort ality in patients with acute myocardial infarction. $N$ Engl f Med 1992;327:678-84.

9 Mathisen P, Hall C, Simonsen S. Comparative study of atrial peptides ANF (1-98) and ANF (99-126) as diagnostic markers of atrial distension in patients with cardiac disease. Scand $\mathcal{F}$ Clin Lab Invest 1993;53:41-9.

10 Lerman A, Gibbons RJ, Rodeheffer RJ, Bailey KR, McKinley LJ, Heublein DM, Burnett JC Jr. Circulating $\mathrm{N}$-terminal atrial natriuretic peptide as a marker for symptomless

11 American Society of Echocardiography Committee on Standards, Subcommittee on Quantitation of TwoDimensio quantitation of the left ventricle by two dimensional echocardiography. $₹ \mathrm{Am}$ Soc Echo 1989;2:358-67.

12 Sundsfiord JA, Thibault G, Larochelle P, Cantin M Identification and plasma concentrations of the $N$ Identification and plasma concentrations of the $\mathbf{N}$ terminal fragment of atrial natriuretic

13 Gaudron P, Eilles C, Kugler I, Ertl G. Progressive left ventricular dysfunction and remodeling after myocardial infarction. Potential mechanisms and early predictors. Circulation 1993;87:755-63.

14 Gruppo Italiano per lo Studio della Sopravvivenza nell'Infarcto Miocardico. GISSI-3: Effects of lisinopri and transdermal glyceryi trinitrate singly and together on 6-week mortality and ventricular function after acute myocardial infarction. Lancet 1994;343:1115-22.

15 Ferguson JJ. Meeting highlights: ISIS 4. Circulation 1994; 89:545.

16 Konstam MA, Rousseau MF, Kronenberg MW, Udelson JE, Melin J, Stewart D, et al for the SOLVD investigators. Effects of angiotensin converting enzyme inhibitor enalapril on long-term progression of left ventricular dysfunction in patients with heart failure. ventricular dysfunction in

17 Konstam MA Kronenberg MW, Rousseau MF, Udelson JE, Melin J, Stewart D, et al for the SOLVD investigators. Effects of the angiotensin converting enzyme inhibitor enalapril on the long-term progression of left ventricular dilatation in patients with asymptomatic systolic dysfunction. Circulation 1993;88:2277-83.

18 The CONSENSUS trial study group. Effects of enalapril on mortality in severe congestive heart failure. $N$ Engl f Med 1987;316:1429-35.

19 The SOLVD investigators. Effect of enalapril on survival in patients with reduced left ventricular ejection fractions and congestive heart failure. $N$ Engl f Med 1991; 325:293-302.

20 Cohn JN, Johnson G, Ziesche S, Cobb F, Francis G, Tristani F, et al. A comparison of enalapril with hydralazine-isosorbide dinitrite in the treatment of chronic congestive heart failure. $N$ Engl $₹$ Med 1991;325: 303-10.

21 The acute infarction ramipril efficacy (AIRE) study investigators. Effect of ramipril on mortality and morbidity of survivors of acute myocardial infarction with clinical cuidence of heart failure. Lancet 1993;342:821-8.

22 The SAVE investigators. Effect of captopril on mortality and morbidity in patients with left ventricular dysfunction after myocardial infarction. Results of the Survival and Ventricular Enlargement Trial. N Eng $\mathcal{f}$ Med 1992; 327:669-77.

23 Pflugfelder PW, Baird MG, Tonkon MJ, Dibianco R, Pitt B. Clinical consequences of angiotensin-converting enzyme inhibitor withdrawal in chronic heart failure: A double-blind placebo-controlled study of Quinapril. f Am Coll Cardiol 1993;22:1557-63.

24 Raine AEG, Erne P, Bürgisser E, Müller FB, Bolli P, Burkhart F, Bühler FR. Atrial natriuretic peptide and atrial pressures in patients with congestive heart failure. N Engl $₹$ Med 1986;315:533-7.

25 Omland T, Bonarjee VVS, Nilsen DWT, Sundsfiord JA, Lie T, Thibault G, Dickstein K. Prognostic significance of N-terminal pro-atrial natriuretic factor (1-98) in acute myocardial infarction: comparison with atrial acute myocardial infarction: comparison with atrial natriuretic factor (99-126)

26 Hall C, Rouleau JL, Klein M, et al. N-terminal pro-atrial natriuretic factor (PRO-ANF)-A uniquely powerful predictor of long-term outcome after myocardial infarction [abstr]. $\mathcal{F} \mathrm{Am}$ Coll Cardiol 1993;21:270A. 